\title{
22. Hidden Expenses in Graduate School: Navigating Financial Precarity and Elitism
}

\author{
Devon Cantwell-Chavez ${ }^{a}$ and Alisson Rowland ${ }^{\text {b,1 }}$ \\ University of Ottawa ${ }^{a}$ University of California, Irvine ${ }^{b}$
}

When applying to political science programs, prospective applicants often consider tuition, cost of living, and assistantship stipends. (See chapter 3 for additional insight into these considerations during the application process, and chapter 23 for more insight about grant applications.) However, there are many "hidden" expenses that creep up during the course of a program which can create significant financial barriers for many students. This chapter discusses additional costs to anticipate throughout a political science $\mathrm{PhD}$ program, along with both traditional and creative ways to pay for these expenses. An important caveat is that the usefulness of this advice will vary pending many factors including your class background, documentation status, nationality, family obligations, and so on. Despite giving advice for successfully navigating these expenses, we strongly condemn systematic financial barriers to graduate school as they not only actively harm students' fiscal and mental well-being, but also limit access for historically marginalized groups. Hence we conclude by encouraging those in positions of power, including faculty, administrators, and organizational leaders, to promote reforms that minimize financial distress and increase access.

\section{Funding Types and How to Use Them}

\footnotetext{
${ }^{1}$ Both authors contributed equally to this piece.
} 
Some funds are single-time applications, whereas others are renewable. Knowing the frequency, and form, of funding opportunities is necessary to choosing the best option for you. There are two primary forms of funds.

- Internal funding sources refer to all opportunities found within your university including:

- Department-based funds, school-based funds, university-wide funds, grants associated with university-affiliated research centers and/or labs, and one-off occasions offered by your university. ${ }^{2}$

- External funding sources refer to all other opportunities, including:

- Funds associated with other research centers, governmental or non-governmental organizations, or professional bodies such as American Political Science Association (APSA) and International Studies Association (ISA).

As important as identifying funding sources is knowing the different ways you can receive these funds. There are two primary ways:

- Direct coverage, where the money is provided upfront and prior to needing to spend it.

- Reimbursement-based, where you spend your own funds first, provide receipts to the designated party, then wait to be reimbursed for the total sum.

If funding is reimbursement based, you will need an accounting system to manage receipts of what was purchased, and when. We have created a template to reference when tracking expenses. ${ }^{3}$ Regardless of the disbursement method, it is always a good idea to keep detailed account of the materials you submit, the notification timeline, how the money is meant to be used, and any other unique regulations or instructions.

\footnotetext{
${ }^{2}$ This is not an exhaustive list of internal opportunities. Some other places to check at your institution include: graduate divisions, program offices, unions, student government, and individual professors.

${ }^{3}$ https://bit.ly/ConferenceBudgetWorksheet
} 
While these are the two most common methods, funding distribution methods will vary by organization. The rising utilization of reimbursements means the reality for many is having to pay out of pocket to perform expected scholarly duties (e.g. conferences, invited talks, data collection). Reimbursement can take anywhere from a few weeks up to 8 or 9 months (@SchutzAustin 10:30 AM). This places disproportionate burdens on first-generation students and students from historically low-income backgrounds who may have less access to funds and safety nets, or who may even have significant responsibilities in providing funds to parents and other family members. (See chapters 56-63 in the section Strategies for Addressing IMplicit Bias, Harassment, and Assault, which provide additional insight into the way financial concern affects students with different intersectional identities.) Failing to meet requirements to receive the reimbursement can result not only in lost funds, but also in an inability to apply for the opportunity in the next cycle. To help you decide when and how to use funds, we discuss standard and hidden fees associated with graduate school.

\section{Standard Costs}

Some costs are fairly expected, such as conference travel, workshops, or job interview expenses, whereas others like dissertation filing fees or research expenses can be unanticipated. Being aware of the different costs you may incur as you progress will maximize your financial autonomy, as these expenses are often not articulated to prospective and new $\mathrm{PhD}$ students.

\section{Conferences and Workshops}


Conferences are a recurring expense to consider. On average, you should try to secure funding to attend at least one conference or workshop per year. A guide and sample budget is listed at the end of this chapter. ${ }^{4}$ Some conference expenses, such as hotel, flight, meals, and transportation, are obvious. However, there are other expenses that need to be factored in depending on your circumstances. These expenses include childcare, professional clothing, visas and other paperwork, poster printing, and business cards. Do not overlook potential temporary costs. For example, many hotels charge an "incidental fee" and hold that amount on your card for three-to-five days after check-out. Call the hotel in advance to ask about this fee, as the amount can range between $\$ 15-\$ 300$ (or higher). If you are paying with a debit card, the incidentals fee can sometimes be higher than it would be if you use a credit card. Common ways to offset the costs of travel are identifying internal and external travel grants, becoming a member of the sponsoring association, and registering early.

\section{External Travel Support}

For external travel support, a number of conferences, including APSA and the International Studies Association (ISA), offer travel grants. Some conference sections, which are groups dedicated to subjects or issue areas, also offer funding support. We have created a list of common funding resources. ${ }^{5}$ Another way to receive fundings support is through volunteering. Some conferences, such as ISA, will issue calls for volunteers and offer to waive registration and possibly even membership fees. These methods of external funding are usually available multiple times, though some may provide one-time-only support across your graduate career. For funds that are only offered once, you may want to consider saving your application for an

${ }^{4}$ https://bit.ly/ConferenceBudgetGuide

${ }^{5}$ https://bit.ly/ConferenceFundingResources 
expensive conference (eg. one that requires international travel or an extended stay in a high-cost city) or to attend at a strategic time, perhaps near the end of your program when on the job market.

Many conferences are hosted by professional organizations, which offer memberships. In addition to providing access to online forums, resources, and scholarships, membership usually also discounts registration fees. There are also conference mentorship programs such as the ASPA Founders Fellows program, the ISA Pay-It-Forward program, and the ISA Global South Mentorship program, which provide travel assistance along with mentorship. These programs, and others, can be found in the common funding resources guide. Finally, organizations like ISA are beginning to defray child care expenses with both subsidized child care services and grants to make attendance more affordable. Chapter 21 provides additional valuable tips on budgeting and grappling with the financial barriers of conferences.

\section{Internal Travel Funds}

In addition to external funding sources, institutional resources can play a major role in making conferences affordable. Dr. Anna Meier discusses variability in conference funding for students in her 2019 blog post on this topic. As of that year, as the graph below illustrates, respondents' institutions ranged from no guaranteed funding per year to around $\$ 2,200$ per year (Meier 2019). 


\section{Graph 1: Guaranteed Funds Per Year, Political Science Ph.D. Programs}

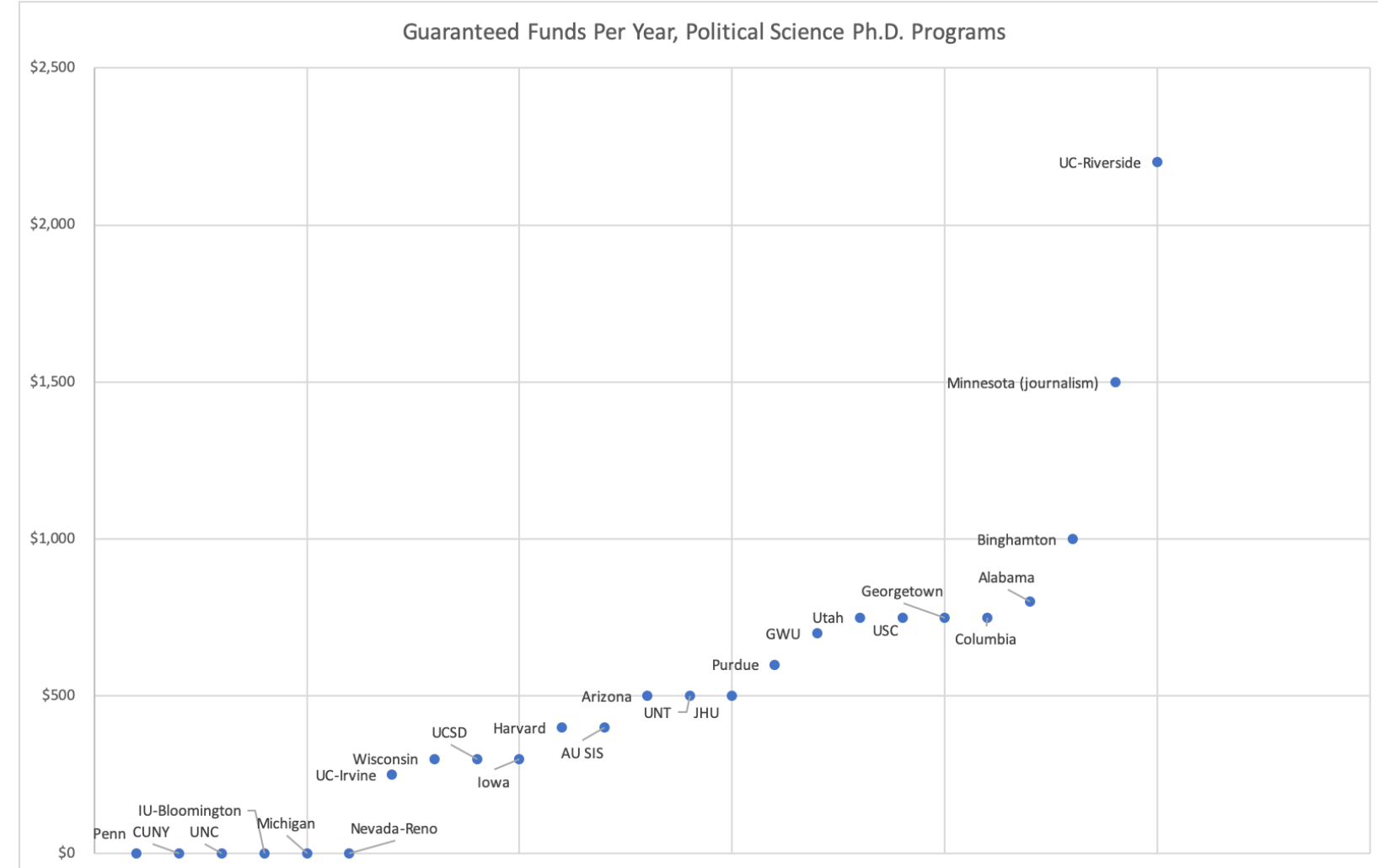

Source: (Meier 2019)

Although not a formal study, Meier (2019) provides a good picture of how varied institutional support can be and what to expect. Graduate divisions, colleges or schools, unions, and student government associations within your university may have a general pool of funds available for all graduate students to support their professional development. If you are a member of an ethnic or racial group that has been historically marginalized on campuses, you may also be able to access funding through ethnic and racial diversity resource centers (ex: Black Student Union, Movimiento Estudiantil Chicanx de Aztlán (MEChA)). These funds can be “once per lifetime" or renewable. If access is structured as first-come, first-served, you will want to apply for the funding as soon as you are eligible to apply. Often, you do not need to be accepted 
to your conference yet to apply for the funding, although check specific requirements at your institution. In other cases, there may be a lottery system to determine who receives funding.

Your area of study may also open you up to funding opportunities. For example, your university may have cultural and/or language centers. Teaching and learning centers may also provide grants if you plan to participate in pedagogy-focused professional development workshops. These centers often receive federal, state, and private grants and offer various opportunities for students to apply for funding throughout the year.

Finally, some professors may have research or conference funds that they may or may not be permitted to use to support their graduate students. If you are working closely with a professor on a paper that will be presented at a conference, it may be worth asking if funds are available to support your attendance. Research funds from professors can sometimes be used to cover travel costs until you can be reimbursed. Ask faculty about this option early to determine if this support is available to you, and to learn of restrictions or stipulations attached to it.

\section{Stretching Out Your Dollars}

Even in generous programs, it is unlikely that you will receive funding adequate to pay for the entirety of your conference participation. A common refrain graduate students often hear is "just put it on a credit card." If you have access to lines of credit, consider a credit card that rewards purchases with airline miles or a cash back percentage, which can help to defray future conference expenses. Small loans are a similar option. Note, educational loans will only be available to you if you have not met your full maximum, also called "cost of attendance," for the year. Unfortunately both of these options pose immense difficulties for low-income, international, and undocumented students. While we are ethically and morally opposed to the 
financial power systems that pressure many students into taking on this additional debt, we do include it as an option in this chapter because it is a common way that graduate students make ends meet.

An option that is more accessible is sharing expenses with colleagues. You may also be able to reduce transportation costs by coordinating arrival and departure from the conference site and splitting expenses with colleagues, by taking public transportation, or by driving. As you will notice, it can be harder to find grants that cover the cost of food. The good news about conferences is that most of them are located in downtown locations with nearby convenience stores. Stocking up on snacks and caffeinated beverages is thrifty. If you are able to walk a few blocks, everything will be two-to-three times less expensive than near the hotel.

A catch-22 with funding is that the earlier you can pay for expenses, the cheaper it is. For example, there are usually early-bird registration fees that can save you hundreds of dollars. If you are tight on funds to pay for upfront costs, talk to the conference organizers. Some conferences require that you register by a certain date in order to remain on the program. If you reach out and explain that you cannot pay the registration fee until a later date, they can often work with you to pay the registration later when you have funds available.

Finally, you get what you pay for with discount travel airlines. Read your terms and conditions carefully because you might get nickeled and dimed for bringing a carry-on bag or choosing a seat. You may also have your flight itinerary canceled or changed, risking missing your panel. If you choose a discount airline that has these potential risks, you may want to consider adding travel insurance. 


\section{Hidden Costs}

Beyond conferences, you will likely uncover an array of hidden costs before graduating. In this section, we will discuss some of the most common ones as well as options for covering these expenses.

First, even if you are "fully funded," your stipend and tuition waiver typically will not cover quarterly or semester fees. Sometimes these fees must be paid to the department, and sometimes the university. These fees may include expenses such as union dues and healthcare premiums, as well as various building, lab, or service usage fees. These expenses can range from a few hundred to thousands of dollars each term. Some universities assess the fees at the start of the term, others towards the middle or end of each term. Current students or department staff should be able to help you find the due dates and cost breakdowns for your specific program.

Second, books are often not provided. Some professors will generously assign articles or books that can be accessed through university library services. If this is not the case, they will often put course books on "reserve" at the library, which allows you to read and/or scan the chapters needed for class. You can also ask the professor or a student who has previously taken that course if they have an extra copy of the text that you can borrow. Another option is to split the cost of the books with one or multiple students and develop a system for sharing them.

Third, research software and fieldwork expenses are critical tools that you will need to complete milestones in your program. Research software costs can be mitigated with open-access statistical software options like R, Tableau Public, QGIS, but such options often come with limitations in either ease of use or function. Additionally, you may need specialty software like Stata, SPSS, Nvivo, Atlas.ti, and Covidence. Sometimes, your school may have a 
license for student use in a virtual lab, or for a discounted or free account. You may also be able to sign up for 30-90 day free trials, which may be an option for short-term projects. Librarians or staff will often help you navigate available software options that meet your needs.

Fieldwork and research expenses can also be significant. Some common expenses include survey or experiment incentives, travel costs, transcription costs, translation costs, and even publication costs (if you want to publish open access research). When fieldwork involves travel, some of the sources of funding in the conference section may be applicable. Small grants may also cover expenses.

Fourth, there are many costs that sneak up on graduate students at the finish line, including dissertation filing fees and regalia. You should reach out to recently graduated students from your program to ask about final year fees. Some graduate students have been able to negotiate the cost of regalia as part of their start-up package if they are expected to wear it while participating in convocations and graduation ceremonies. Many students will also manage expenses by renting or borrowing regalia. Finally, it is also important to pay attention to when you will lose access to health care and other benefits if you are a funded graduate assistant. Be sure to discuss this timeline with your dissertation advisor and schedule your defense and filing according to your needs.

Fifth, be aware that you may experience gaps in employment during your graduate career. If you are a funded student, your first paycheck may be delayed by several months into the term. Moreover, many graduate assistantships are nine-month positions that provide no financial support beyond the academic year. If you do not secure a summer teaching or research position, you may have a lapse in payment after the academic year ends, typically in May or June. Be sure 
to ask your advisor and professors about opportunities for summer employment to help cover expenses. If you pursue a traditional academic career, be aware that you will also likely have a lapse in payment between your last graduate paycheck and your first paycheck as a professor. If this lapse leaves you strapped for funds or affects your access to credit, make plans for how to cover moving expenses as you may need to relocate across the country (or the world). Most colleges and universities have historically reimbursed new employees for relocation expenses, but some are willing to negotiate a moving stipend or signing bonus in advance instead. Another potential negotiating tactic is to request a July 1st start date rather than August or September. (See chapter 48 for additional advice on negotiating your first position.)

\section{Conclusion}

This chapter offers an overview of the anticipated, and unanticipated, costs associated with doctoral programs and some strategies to reduce them. While some of these costs may be covered by your institution, many are not. Graduate school requires four to ten years, and stipends are rarely sufficient to make ends meet for one person, let alone those with other family or financial obligations. The practices outlined here amount to survival tactics to avoid extreme financial distress. The onus is on the academy at large to shift the culture around reimbursement, which is an elitist practice, towards direct cost coverage. In researching this chapter, we were startled to learn that even within universities, departments have actively chosen to retain reimbursement policies, even when they have the flexibility and resources for direct pay. Deans, chairs, and graduate studies directors can be pivotal in changing these policies and practices. Faculty can also take an active role in helping to minimize harm to graduate students by actively 
checking in with advisees about conference and workshop affordability, providing support for grant writing and identifying other funding opportunities, and assisting with cost coverage when feasible. It is not enough to admit marginalized and vulnerable scholars, the academy must also provide the necessary tools, resources, and practices for them to thrive. As students provide labor as teaching assistants and research assistants in addition to their own research output, universities should provide direct cost coverage for costs associated with these tasks; this includes conferences, professional memberships, course materials, dissertation filing fees, and tuition fees, among others. While there are other ways students are marginalized and forced out of the academy, financial precarity causes undue physical and mental stress, along with threats to livelihood. Adopting full cost coverage policies is a necessary and direct step in reducing financial precarity for graduate students.

\section{References}

Meier, Anna. 2019. “Grad Student Conference Funding: A Preliminary Lay of the Land.”(Blog). http://annameier.net/grad-student-conference-funding-a-preliminary-lay-of-the-land/.

Schutz, Austin (@SchutzAustin).2021. "Hey everyone, welcome back to 'how do I gradschool?"” (Twitter). 12.13. 10:30 AM. https://twitter.com/SchutzAustin/status/1470461253378318338?s=20 